\title{
Entrevista com Fernanda Coelho Liberali ${ }^{1}$
}

Fernanda Coelho Liberali é Doutora em Linguística Aplicada pela PUC/SP e atua como professora do Programa de Estudos Pós-Graduados em Linguística Aplicada e Estudos da Linguagem e no Departamento de Inglês dessa mesma instituição. Atualmente, é a representante brasileira da International Society for Cultural and Activity Research (ISCAR). É coordenadora geral do Programa de Extensão Ação Cidadã e diretora do Instituto Ação Cidadã. É membro do GT de Formação de Educadores na Linguística Aplicada vinculado à ANPOLL. Em programas de extensão, ministra e coordena cursos sobre formação de educadores, sobre teorias de ensino-aprendizagem e sobre questões de cidadania. Atua também como consultora para instituições públicas e privadas do estado de São Paulo. Sua pesquisa aborda questões sobre a formação contínua de educadores com foco na teoria da atividade, reflexão crítica e na análise do discurso, com foco na argumentação.

Soletras: Considerando sua área de pesquisa e seu envolvimento com formação continuada de professores, como você vê a pesquisa sobre formação do professor de línguas no país? Há desafios a serem enfrentados por pesquisadores da área?

Penso que, nos últimos anos, muito tem sido feito em termos de pesquisas na área de formação de professores de línguas no país e no mundo. É possível perceber em diferentes revistas e livros que há uma crescente preocupação em trazer a prática dos professores e dos formadores de professores para o debate sobre como ampliar as perspectivas e a qualidade da educação. Grupos de pesquisadores como o Grupo de Trabalho de Formação de Professores de Línguas da Associação Nacional de Pós-Graduação e Pesquisa em Letras e Linguística (ANPOLL), assim como eventos como o Congresso Latino-Americano de Formação de Professores de Línguas (CLAFPL), têm oferecido visibilidade e intercâmbio para que pesquisadores na área possam expor seus estudos e descobertas.

Contudo, a questão que se mantém forte é: quanto dessas pesquisas e de seus resultados tem contribuído para o cenário de ensino de línguas do país. Há, cada vez mais, uma evidente precarização do trabalho dos professores em geral, e dos professores de línguas em especial. Projetos em pequena escala parecem apontar caminhos, no entanto, pouca expansão parecem receber e, por vezes, percebe-se que as práticas escolares mantêm-se fiéis a modos de agir há muito criticados e considerados impróprios aos contextos de ensinoaprendizagem atuais.

${ }^{1}$ Entrevista concedida às professoras Inés Kayon de Miller e Isabel Cristina Rangel Bezerra. 


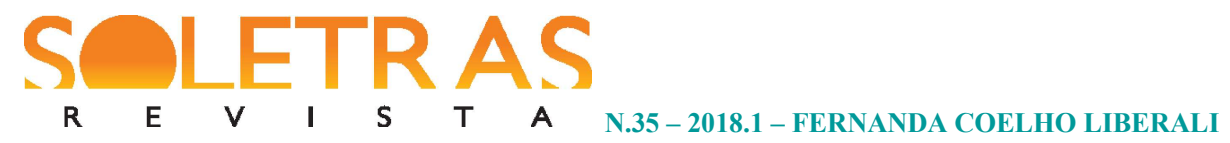

Um grande desafio para todos os pesquisadores é pensar em como relevantes projetos de formação podem efetivamente se tornar parte das políticas de formação em escolas públicas e privadas do país. Caberia inclusive uma reflexão sobre que pesquisas poderiam investigar a capilaridade dos resultados de projetos bem sucedidos nas práticas escolares em geral.

Soletras: Como surgiu o grupo de trabalho integrado por formadores de educadores em Linguística Aplicada e como ele tem contribuído para a área de formação do professor de línguas?

O grupo surgiu no início dos anos 2000 com a reunião de um ainda pequeno grupo de pesquisadores da área de Linguística Aplicada que estava interessado em estudar a formação de professores. Na época, aquele grupo decidiu formar um Sub-Grupo de Trabalho (GT), dentro do GT de Linguística Aplicada na ANPOLL, que tivesse condições de fortalecer os estudos e os intercâmbios na área de formação. Considerada por muitos como a prima pobre da área, a formação de professores parecia ao grupo um importante tema a guiar pesquisas e estudos compartilhados. A observação da realidade mostrava que os resultados de pesquisa pareciam muito distanciados das práticas de sala de aula e uma demanda real por formar professores a partir de compreensões cada vez mais profundas sobre o seu trabalho também deveria ser objeto de investigação.

Para fortalecer o grupo de pesquisadores, participações em eventos, pesquisas e publicações conjuntas foram pensadas com a intenção de criar uma base de compreensão da temática de formação de educadores. A partir dessas interlocuções, a área se expandiu e criou o Congresso Latino-Americano de Formação de Professores de Línguas (CLAFPL) como um evento latino-americano para criar oportunidade de que pesquisadores seniores e em formação pudessem se reunir no intuito de compartilhar suas experiências e pesquisas.

As práticas conjuntas desses pesquisadores viabilizaram a criação de um GT de Formação de Educadores em Línguística Aplicada. Com isso, o grupo de pesquisadores, já ampliado ao longo dos anos, pode crescer ainda mais e se solidificar como um grupo de estudiosos com perspectivas de colaborar para a formação de professores no país. 


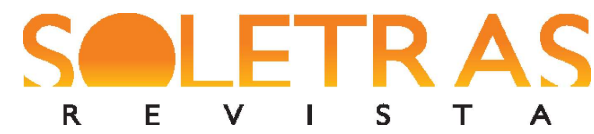

N.35 - 2018.1 - FERNANDA COELHO LIBERALI

Soletras: Ainda a partir de seu olhar de pesquisadora, quais são as tendências que você percebe na formação docente inicial e contínua de professores oferecida no Brasil?

Considero que as formações inicial e contínua de educadores têm recebido especial atenção nos últimos anos. Programas oficiais e privados, além de inúmeros cursos de extensão, têm sido criados como uma forma de expansão das atividades formativas de educadores. Além disso, a relação entre estudantes de cursos de licenciatura com professores atuantes na prática tem sido vista como um instrumento de formação recíproca.

Desde os anos 90, a questão da reflexão na formação dos educadores assumiu no Brasil e no mundo uma valorização profunda. Ainda que a concepção de reflexão seja muito diferente nos variados grupos, pesquisas e publicações, a temática ainda recebe importante atenção.

$\mathrm{Na}$ minha perspectiva, contudo, há uma demanda crescente por pensar a formação a partir das demandas históricas e das práticas que podem servir a uma sociedade com mais justiça social. Em nossa sociedade, a globalização excludente parece transformar nossa forma de ser no mundo, como apontam Blommaert (2010), Santos, M. (2000/2003), Santos, B. (2008) e Souza (2017). Em um país em que, segundo a Oxfam ${ }^{2}$ (janeiro de 2018), os cinco homens mais ricos do Brasil possuem a mesma riqueza que a renda da metade mais pobre da população brasileira, é preciso que as formas de ação em sala de aula ofereçam oportunidade para a formação de alunos críticos e ativistas. Mas isso só será possível se os professores e seus formadores tiverem a compreensão do significado histórico de suas ações.

Obviamente a formação de alunos com repertórios multimodais (BLOMMAERT, 2010; BUSCH, 2015, KRESS, 2010, LIBERALI, LIBERALI et al, 2017) para viver a vida em nossa sociedade, no caso, tendo o ensino-aprendizagem de línguas como mediador é fundamental. Contudo, apenas teremos sujeitos atuantes na construção de um mundo justo, quando a apropriação desses recursos vier marcada pela discussão dos valores que neles são incutidos nos diferentes espaços-tempo (BLOMMAERT, 2010) nos quais os alunos e seus

\footnotetext{
${ }^{2}$ A Oxfam foi fundada em 1942, quando um grupo de pessoas se reuniu para uma campanha de arrecadação de alimentos com o objetivo de diminuir a fome e amenizar os danos causados pela Segunda Guerra Mundial. Nas décadas seguintes, a Oxfam passou a atuar em outros continentes, chegando à África, Ásia e América Latina. Além do trabalho humanitário, que já desenvolvia desde 1942, passou a apoiar e implementar projetos de desenvolvimento de longo prazo e a realizar campanhas que buscam conscientizar e incentivar mudanças necessárias para a redução da pobreza e desigualdade e a promoção da justiça social. Fonte: https://www.oxfam.org.br/quem-somos/oxfam-no-mundo
} 
professores estão inseridos. Para que isso seja possível, é basilar que o processo de formação vá além de pensar a aprendizagem da língua e a reflexão sobre questões críticas. Para ser transformador e ousado, no sentido de Freire (1970) e Stetsenko (2017), é preciso que a formação ofereça oportunidade para que atividades de ensino-aprendizagem se tornem palco para a vivência e a reflexão de como os alunos se apropriam de múltiplos recursos para significar no processo de viver. Como esses recursos contribuem para a formação de um sujeito preocupado com as condições de opressão que o circundam?De que maneira os modos de formar professores se ocupam desse processo? Essa é, para mim, uma necessária tendência a ser assumida nas formações iniciais e contínuas.

Soletras: Você poderia destacar os principais aspectos do seu trabalho de pesquisa e de formação crítico-reflexiva de professores?

Minha preocupação sempre foi voltada à constituição crítica dos sujeitos: alunos, professores, coordenadores, diretores, formadores de educadores e pais. Nos últimos anos, alguns pontos têm sido centrais para o trabalho desenvolvido pelo Grupo de Pesquisa Linguagem em Atividades no Contexto Escolar (LACE) ${ }^{3}$, que lidero junto com a Profa. Dra. Maria Cecília Magalhães:

1. Formação de professores de todas as áreas para e pelo trabalho com linguagem. Os integrantes do GP LACE, desde 1993, têm se ocupado de cursos de formação de formadores (coordenadores, diretores, formadores de diretorias, supervisores ${ }^{4}$ ) por meio de reflexões sobre questões da linguagem. Isso implica tanto em um trabalho sobre a linguagem na formação de educadores quanto no trabalho sobre a linguagem no ensino-aprendizagem em diferentes áreas. Várias são as pesquisas (como pode ser visto pelas teses e dissertações que Cecília e eu orientamos e por nossas publicações) e os projetos (Programa Ação Cidadã - $\mathrm{PAC}^{5}$ e Projeto Digit-M-ED ${ }^{6}$ ) desenvolvidos pelo grupo ao longo dos anos.

\footnotetext{
${ }^{3}$ Para mais informações: MAGALHÃES, M. C. C.; LIBERALI, F. C. Grupo de Pesquisa Linguagem em Atividades no Contexto Escola (LACE): A linguagem na formação de educadores e alunos colaborativos, críticos e criativos. Educação em Foco (Juiz de Fora), v. 1, p. 129-139, 2012.

${ }^{4}$ Por exemplo, o curso O papel do coordenador no processo de desenvolvimento do professor, título de minha dissertação de mestrado, se transformou em curso de extensão da COGEAE/PUCSP, ainda durante o processo de pesquisa de mestrado sobre meu trabalho como coordenadora em uma escola de línguas.

${ }^{5}$ Breve descrição do PAC: Considerando a responsabilidade social da Universidade e a importância da produção colaborativa e crítica de novos saberes na reconstrução de identidades cidadãs, o objetivo geral do Programa
} 


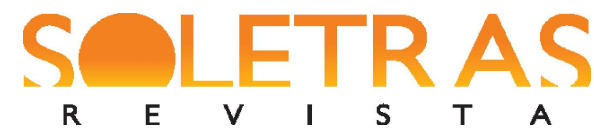

N.35 - 2018.1 - FERNANDA COELHO LIBERALI

2. A formação de formadores. Desde 2002, o GP LACE vem realizando trabalhos para a formação de formadores. No caso, focaliza não apenas os professores universitários, os coordenadores, os diretores, supervisores e formadores de diretorias como formadores, mas professores e alunos como agentes de formação com papel efetivo no contexto e nas práticas escolares. Isso se realiza por meio de constituição de professores como Grupo de Apoio (DANIELS; PARRILLA, 2004), responsável por assumir uma parcela da responsabilidade pela formação de seus colegas. Além disso, a partir do projeto de extensão e pesquisa Digit-M-Ed (LIBERALI, C. LIBERALI et al, 2017; LIBERALI, MAGALHÃES et al, 2017; LIBERALI et al. 2015; DAMIANOVIC et al. 2016; LIBERALI, C. 2015; PÊSSOA 2016; RITTNER, 2014; RITTNER, 2014), temos trabalhado com a formação de alunos como formadores de professores em diferentes atividades do contexto escolar. Essa proposta dá aos alunos oportunidade de se apropriarem de conceitos sobre práticas didáticas, como, por exemplo, a Pedagogia dos Multiletramentos, e contribuir efetivamente na formação de seus professores para a construção de propostas curriculares desencapsuladores. ${ }^{7}$

3. Formação de professores para contextos multilíngues: desde 2008, com a criação do Grupo de Estudos sobre Educação Bilíngue (GEEB), a temática da formação de professores em contextos multilíngues assumiu uma importante relevância para o GP

Ação Cidadã é desenvolver atividades para a compreensão, discussão, transformação e ação referentes ao trabalho dos formadores, coordenadores, professores, diretores, alunos e pais das diferentes instituições envolvidas, pautadas por uma perspectiva de Ação Cidadã. Na terceira fase (2010- 2012), o Programa tem como projetos: 1) "Aprender Brincando", realizado junto a instituições, públicas e conveniadas, de educação infantil de São Paulo; 2) "Educação Multicultural", realizado com crianças, jovens e adultos para o trabalho em línguas internacionais; 3) "Múltiplos Mundos", realizado por meio de eventos e de plataforma virtual para integrar participantes dos vários projetos, educadores e pesquisadores nacionais e internacionais, dentre outros projetos que poderão vir a incorporar o Programa ao longo do próximo triênio (2013- 2015).

${ }^{6}$ Breve descrição do Projeto DIGIT-M-ED Hiperconectando BRASIL. O projeto crítico-colaborativo com comunidades escolares partiu de necessidades declaradas por participantes de projetos de pesquisa já desenvolvidos pelos pesquisadores do Grupo de Pesquisa LACE e relatadas em trabalhos anteriores (LIBERALI, 2013). Desde 2013, a partir do projeto internacional, coordenado por Kontopodis (2011 - 2014) e financiado pelo Projeto de Intercâmbio de Equipes de Pesquisas Internacionais de Marie Curie - União Europeia FP7 (IRSES) (2012-2014), foi desenvolvido um projeto no Brasil, DIGIT-M-ED/Brasil - Transformando o ensinoaprendizagem pelas múltiplas mídias (2013- 2015), atualmente DIGIT-M-ED Hiperconectando Brasil Transformando o ensino-aprendizagem (2016 - 2018).

7 Propostas desencapsuladoras pressupõem que saberes escolarizados, normalmente fixos e marcados por perspectivas únicas e verdades absolutas, podem ser superados a partir de uma ecologia de saberes (SANTOS, 2008) de fontes distintas. Essa diversidade de possibilidades de compreensão cria a oportunidade para a expansão da aprendizagem (ENGESTRÖM, 1987/2002), permitindo a realização do ensino-aprendizagem fora de cápsulas tais como as disciplinas, as fontes e a própria instituição escolar. Nessa linha, esse processo desencadeia um tipo de desenvolvimento humano, em que os atores da escola estendem seus vários saberes para além da escola e os integram em sua vida. 
LACE. Vários pesquisadores (RISÉRIO-CORTEZ, 2007; DAVID,2007; MIASCOVSKY, 2008; MEANEY, 2009; WOLFFOWITZ-SACNHEZ,2009; PRETINI, 2011; AMARANTE,2010; CABABE, 2014; OLIVEIRA, 2016; GUIDI, 2017; LIBERALI, 2013b, 2017; LIBERALI; MEGALE, 2016; GAZZOTTI; LIBERALI, 2014; MEGALE; LIBERALI, 2016). A formação do sujeito multilíngue que se apropria de recursos vários como forma de construir mobilidade (BLOMMAERT, 2010) e participar ativamente em diferentes contextos sociais se tornou foco de uma parcela do GP que tem focalizado questões de formação de professores para a ação em educação bilíngue de elite, para ensino de português para surdos e de libras para ouvintes e para o trabalho com imigrantes e filhos de imigrantes.

O GP LACE vem procurando estar atentos às novas realidades e considerar as implicações que trazem para a formação dos professores. Nossos trabalhos trazem sempre a postura crítico-colaborativa, desenhada e discutida amplamente por Magalhães, como base para todas as nossas ações.

Soletras: Tendo em vista a recente aprovação e homologação da Base Nacional Comum Curricular bem como da mobilização no sentido de que ela seja implementada em curto espaço de tempo, que avaliação você faz da BNCC e como você acha que ela pode impactar a formação do professor de línguas?

Considero fundamental a preocupação de um país com relação ao currículo de suas escolas. Acredito que sejam pertinentes a reflexão sobre o tema e o cuidado constante em refletir sobre que saberes são necessários para o bem viver em sociedade. Penso que uma discussão nacional ampla sobre o que seria uma base de saberes necessários seja muito relevante como um exercício reflexivo nacional. Considerar que as pessoas devem ter direitos a recursos que os permitirão participar da vida social de forma mais ampla e equânime me parece bastante justo.

Isso posto, gostaria de expor que a BNCC não me parece cumprir o papel reflexivo que aponto acima. Seu processo de realização foi traçado em meio a um caos político e ideológico que tornou seu resultado muito mais um objeto de disputa política em um país 
cindido por brigas e oposições intransponíveis, mas que não respondem ao que se pretende ao criar uma base para a formação de alunos, educadores e formadores. Os conteúdos e as proposições da BNCC apresentam contradições e se oferecem a questionamentos fortes, não apenas por terem inconsistências, mas, principalmente, pela sua forma de construção e implementação.

Que reflexões são possíveis de serem feitas com os professores a partir da BNCC? Como a BNCC efetivamente contribui para a formação dos professores do país? De que forma se ocupa da formação de alunos que possam desenvolver um viver mais efetivo? Como as políticas realizadas para sua construção e implementação geraram oportunidade de transformação das práticas escolares?

Nos três últimos anos, o Projeto Digit-M-Ed tem usado as várias versões da base como instrumento para pensar a construção de currículos desencapsuladores com escolas públicas e privadas de São Paulo. A crítica aqui feita se refere não apenas aos conteúdos lá expostos e modificados sem que se entenda bem quais as motivações dessas mudanças. Nossa preocupação tem sido pensar (1) como essa proposta responde ou não às demandas da realidade dos alunos com os quais temos convivido e (2) como podemos repensar as políticas públicas para as efetivas construção e implementação de currículos que se pretendem conectados com as realidades dos sujeitos, mas que pouco tem de efetiva participação deles.

Recentemente, iniciamos uma proposta para um trabalho de formação de professores de língua inglesa na cidade de São Paulo, que não teve continuidade devido à nossa discordância em relação a algumas ações da gestão de seu prefeito (como, por exemplo, apoio a ações do vereador Holiday em visitar escolas com observações sustentadas na temática das Escolas Sem Partido). Naquela oportunidade, reunimos um grupo de formação para o trabalho junto aos professores da rede que contava com pesquisadores, professores e alunos que atuavam no projeto Digit-M-Ed e que tinha experiência com os conceitos ligados a Multiletramentos (New London Group, 1996/2000), Teoria da Atividade (VYGOTSKY, 1934/2001; LEONTIEV, 1977/2014; ENGESTRÖM, 1991/2002), Brincar/Performance (VYGOTSKY, 1930; HOLZMAN, 2009; LOBMAN; O’NIEL, 2011). Esses participantes do grupo de formação tiveram forte e importantíssima atuação na formação do grupo de professores da rede de escolas municipais durante o tempo em que estivemos a frente do projeto. Infelizmente, a descontinuidade do projeto impossibilitou uma visão de como esse modo de operar poderia vir a se tornar uma política pública de formação de professores que 
contasse com a participação de professores e alunos como efetivos formadores oficiais de outros professores.

Esse tipo de projeto pode oferecer uma abertura para efetivamente considerar as vozes daqueles que estão diretamente envolvidos com o fazer na escola e com a vida que se vive no dia a dia.

Soletras: Como você se posiciona em relação à Política Nacional de Formação de Professores proposta pelo governo federal EM 2017 ?

Como apontei em relação à $\mathrm{BNCC}$, penso que este seja mais um projeto que tem intenções pouco interessadas na real formação de educadores, mas mais centradas em uma resposta às demandas políticas de nosso momento conturbado. A ausência de uma consulta a praticantes e pesquisadores e de ações compartilhadas com a universidade parece mostrar a não valorização da reflexão conjunta das instituições e dos participantes envolvidos no contexto em foco.

A proposta do PIBID, que certamente está na base dessa sugestão de "residência", vem recebendo inúmeras avaliações ao longo dos anos, referendada por teses, dissertações, trabalhos de Iniciação Científica, livros, artigos e capítulos que mostram estudos cuidadosos sobre o tema. Não percebo na nova proposta uma retomada dos aspectos positivos e negativos e, muito menos, dos desafios e dos alcances desse projeto inicial. O que se vê é que, mais uma vez, um novo programa surge como salvador da situação sem que uma efetiva discussão ampla sobre os resultados daquilo que este que pretende substituir tenha sido realizada.

Nesse sentido, não consigo enxergar nessa proposta outro futuro que não o da resistência. Penso que qualquer formação precisa contar com a participação efetiva dos envolvidos. Quando as associações de pesquisa e várias outras entidades se sentem deixadas de fora do processo, certamente uma dificuldade colaborativa se impõe. Formação de educadores demanda mais do que ações mirabolantes com nomes de efeito. É com extrema dificuldade e com a certeza das contradições do caminho que um projeto de formação precisa ser colocado em discussão e, a partir daí, implementado. Não vi isso acontecer. O que se viu foi a aparição de um novo programa se impondo sobre as práticas em realização.

Mesmo que o projeto tenha uma ampla capacidade de transformação, isso nem entra em debate, se sua forma de construção e implementação desconsidera os setores que vem 


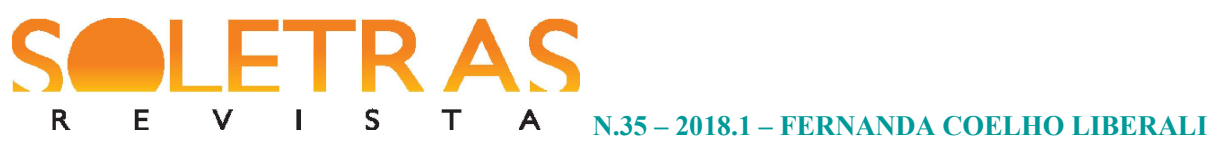

democraticamente participando de projetos que pensam nas formações inicial e contínua de educadores.

Soletras: Professora Fernanda, agradecemos imensamente sua contribuição para a reflexão sobre formação e atuação do professor através de suas respostas. Certamente levará nossas leitoras e nossos leitores a repensarem a formação de professores no Brasil e, esperamos, suas próprias vivências de formadores e professores em formação

Agradeço a oportunidade de partilhar e refletir.

\section{Referências bibliográficas}

AMARANTE, G. B. M. F. Conhecer, vivenciar, desejar: "Perejivanie" no ensino em francês. Dissertação. (Mestrado em Linguística Aplicada e Estudos da Linguagem) Pontifícia Universidade Católica de São Paulo, São Paulo, 2010.

BLOMMAERT, J. The sociolinguistics of globalization. Cambridge, New York: Cambridge University Press, 2010.

BUSCH, B. Expanding the notion of the linguistic repertoire: on the concept of Spracherleben - the lived experience of language. Applied Linguistics. 38 (3), 340-358, 2015. https://doi.org/10.1093/applin/amv030

CABABE, B. S. Multiculturalidade, Multimodalide e Perguntas Argumentativas na aprendizagem e no desenvolvimento de Português como Língua Adicional. Dissertação de Mestrado (Mestre em Linguística Aplicada e Estudos da Linguagem pela Pontifícia Universidade Católica de São Paulo) São Paulo: PUC-SP, 2014.

DAMIANOVIC, M. C., SILVA, A. S., CARRIJO, V. L. S., FARIAS, A. M. Argumentação multimodal entender colaboração: além da materialização linguística no Digit-M-ed. In: Liberali, F. C., Damianovic, M. C. C. C. L., Ninin, M. O. G., Mateus, E., Guerra, M., eds. Argumentação em Contexto Escolar: Relatos de Pesquisa. $1^{\text {a }}$ ed., 237-266. Campinas, São Paulo: Pontes Editora, 2016.

DANIELS, H.; PARRILA, A. Criação e Desenvolvimento de Grupo de Apoio entre Professores. Tradução: Glória Abdalla e Rodrigo Lopes. São Paulo: Edições Loyola, 2004.

DAVID, A. M. F. As concepções de ensino-aprendizagem do projeto político-pedagógico de uma escola de educação bilíngue. Dissertação de Mestrado (Mestre em Linguística Aplicada e Estudos da Linguagem pela Pontifícia Universidade Católica de São Paulo) São Paulo: PUC-SP, 2007.

ENGESTRÖM, Y. (1991) Non scolae sed vitae dsicimus: como superar a encapsulação da aprendizagem escolar. In: DANIELS, H. Uma introdução a Vygotsky. São Paulo: Edições Loyola, 2002. 


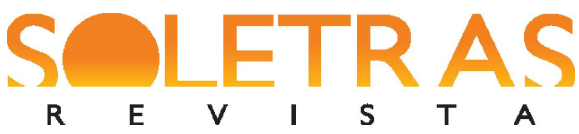

N.35 - 2018.1 - FERNANDA COELHO LIBERALI

FREIRE, P. (1987). A Pedagogia do Oprimido. Rio de Janeiro: Paz e Terra, 1970.

GAZZOTTI, D. Resolução de Conflitos em Contextos de Educação Infantil Bilíngue. 2011. Dissertação (Mestrado em Linguística Aplicada e Estudos da Linguagem). Pontifícia Universidade Católica de São Paulo, São Paulo, 2011.

; LIBERALI, F. C. Conflict Resolution in the context of early childhoood bilingual education- towards a multicultural development.IN: RBLA. Belo Horizonte, 2014, v. 14, n. 2, p. 313-334.

GUIDI, F. C. L. Concepções De Educação Bilingue De Elite Em Três Escolas Privadas Do Estado De São Paulo. Dissertação (Mestrado em Linguística Aplicada e Estudos da Linguagem) - LAEL, Pontifícia Universidade Católica de São Paulo, São Paulo, 2017.

HOLZMAN, L. Vygotsky at work and play. New York, Routledge, 2009.

KRESS, G. Multimodality: A social semiotic approach to contemporary communication. London: Routledge, 2010.

LEONTIEV, A. N. Activity and Consciousness.Philosophy in the USSR.Problems of Dialectical Materialism, Progress Publishers, 1977.Disponível em $<$ http://www.marxists.org/archive/leontev/works/1977/leon1977.htm>. Acesso em: 15 de agosto de 2014.

LIBERALI, C. C. Análise teórico-prática sobre o multiculturalismo e a colaboração como formas de lidar com as diferenças. Trabalho de Conclusão de Curso. USP: SP, 2015.

LIBERALI, F. C. Globalization, Superdiversity, Language Learning and Teacher Education in Brazil. In: BANEGAS, D. L. (Org.). Initial English Language Teacher Education: international perspectives on research, curriculum and practice. $1^{\text {a }}$ ed. New York: Bloomsbury, v. 1, p. 177-191, 2017.

. Argumentação em Contexto Escolar. Campinas, SP: Pontes Editores, 2013.

. Student-teachers and Teacher-educators Experience New Roles in Pre-service Bilingual Teacher Education in Brazil.In: Christian Abello-Contesse, Paul M. Chandler, María Dolores López-Jiménez, Rubén Chacón-Beltrán. (Org.). Bilingual and Multilingual Education in the 21 st Century. $1^{\text {a }}$ ed. Estados Unidos: Multilingual Matters, v. 1, p. 231-255, 2013.

; LIBERAli, C. C.; PADRE, B. T.; SANTOS, J. A. A. Mobilidade e Práticas Translíngues na Construção de um Mundo com Justiça Social: um Estudo no Projeto DIGITM-ED. In: ROCHA, C. H.; EL KADRI, M. S.; WINDLE, J. A. (Orgs.). Diálogos sobre tecnologia educacional: Educação linguística, mobilidade e práticas translíngues. Campinas, SP: Pontes, p. 237-267, 2017.

.; MAGAlHÃES, M. C. C.; MEANEY, M. C.; SANTIAGO, C.; CANUTO, M.; AMARAL, F.; CABABE, B. S.; SANTOS, J. A. A. Enhancing Multimedia Use In Public Middle and High Schools in São Paulo/ Brazil: A Critical Collaborative Methodological 


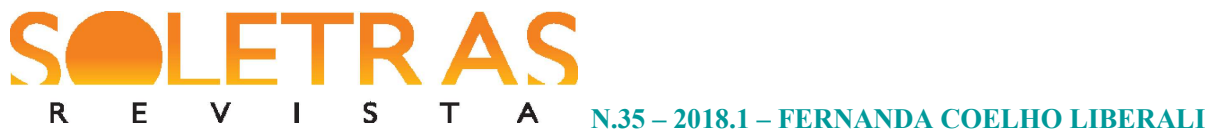

Perspective. In: KONTOPODIS, M.; VARVANTAKIS, C.; WULF, C. (Orgs.). Global Youth in Digital Trajectories. 1 ${ }^{\text {a }}$ ed. London: Routledge, v. 1, p. 127-145, 2017.

; MEGALE, A. H. Elite bilingual education in Brazil: an applied linguist's perspective. Colomb. Appl. Linguist. J., 18(2), p. 95-108, 2016.

; MAGalhães, M. C. C.; MEANEY, M. C.; SANTIAGO, C.; CANUTO, M.; SANTOS, J. A. A. Projeto DIGIT-M-ED Brasil: uma proposta de desencapsulação da aprendizagem escolar por meio dos Multiletramentos. Prolíngua (João Pessoa), v. 10, p. 2$17,2015$.

LOBMAN, C.; AND O’NIEL, B. E., (eds.) Play and Performance: play and cultural studies. USA: University Press of America, 2011.

MEANEY, M. C. Argumentação na formação do professor na escola bilíngue. Dissertação. (Mestrado em Linguística Aplicada e Estudos da Linguagem) - LAEL - Pontifícia Universidade Católica de São Paulo, São Paulo, 2009.

MEGALE, A. H.; LIBERALI, F. C. Caminhos da educação bilíngue no Brasil: perspectivas da linguística aplicada. RAÍDO (ONLINE), v. 10, p. 9-24, 2016.

MIASCOVSKY, H. W. A produção criativa na atividade sessão reflexiva em contextos de educação bilíngue. Dissertação de Mestrado (Mestre em Linguística Aplicada e Estudos da Linguagem pela Pontifícia Universidade Católica de São Paulo) São Paulo: PUC-SP, 2008.

NEW LONDON GROUP. [1996] The Pedagogy of Multiliteracies: Designing Social Futures. v.66, n.1, p.60-92, Harvard Educational Review, 2000.

OLIVEIRA, E. P. Multiculturalidade e colaboração crítica entre surdos e ouvintes na visão de um pesquisador tradutor-intérprete de libras/português. Dissertação de Mestrado (Mestre em Linguística Aplicada e Estudos da Linguagem pela Pontifícia Universidade Católica de São Paulo) São Paulo: PUC-SP, 2016.

PRETINI, A. JR. Enunciados narrativos e performáticos no ensino-aprendizagem com base em atividades sócias: A relação teoria-prática na formação de professores. 2011. Dissertação (Mestrado em Linguística Aplicada e Estudos da Linguagem) - LAEL, Pontifícia Universidade Católica de São Paulo, São Paulo, 2011.

RISÉRIO-CORTEZ, A. P. B. A Língua Inglesa como Objeto e Instrumento Mediador de Ensino-Aprendizagem em Educação Bilíngue. Dissertação de Mestrado (Mestre em Linguística Aplicada e Estudos da Linguagem pela Pontifícia Universidade Católica de São Paulo) São Paulo: PUC-SP, 2007.

RITTNER, G. M. Digit-M-ed Brasil: a realidade possível do uso da tecnologia em sala de aula e suas implicações para desenvolver para habilidades de leitura e escrita em um ambiente de multiletramento. Monografia (Iniciação Cientifica)- Pontifícia Universidade Católica de São Paulo, São Paulo, 2014. 


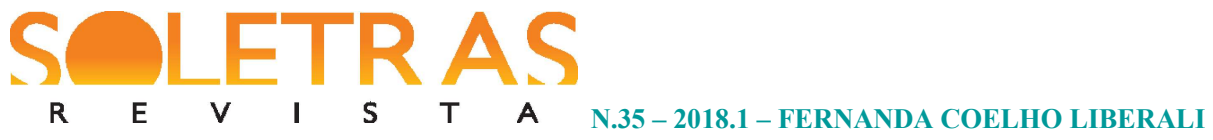

RITTNER, G. M. Interdisciplinaridade além da sala de aula: professores em parceria. Trabalho de Conclusão de Curso (Graduação)- Pontifícia Universidade Católica de São Paulo, São Paulo, 2014.

SANTOS, M. Por uma outra globalização. Rio de Janeiro: Record, 2003.

SANTOS, Boaventura de S. A gramática do tempo: para uma nova cultura política. São Paulo: Cortez, 2008.

SOUZA, J. A elite do atraso: da escravidão à lava jato. Rio de Janeiro: Leya, 2017.

STETSENKO, A. The transformative mind: expanding Vygotsky's approach to development and education. Cambridge: Cambridge University Press: New York, 2017.

VYGOTKY, L. S. (1930). A formação social da mente. São Paulo, Martins Fontes, 1988.

VYGOTSKY, Lev S. (1934). A construção do pensamento e da linguagem. Trad.

Paulo Bezerra. 1. Ed. São Paulo: Martins Fontes, 2001.

WOLFFOWITZ-SACNHEZ, N. Formação de professores para a educação infantil bilíngue. Dissertação de Mestrado (Mestre em Linguística Aplicada e Estudos da Linguagem pela Pontifícia Universidade Católica de São Paulo) São Paulo: PUC-SP, 2009.

Entrevista concedida em 18 de março de 2018. 